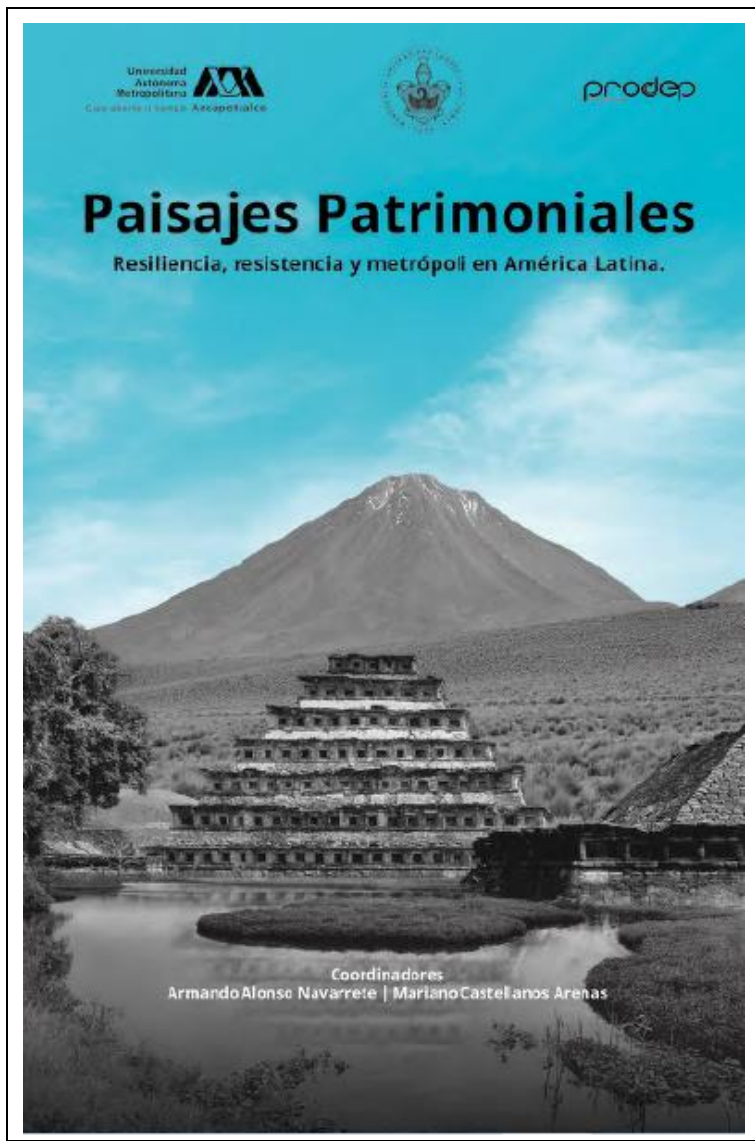

Moreno Pantoja, Carlos (2020).

Hernández García, Yesenia (2020).

ORCID: 0000-0003-2341-150X

\title{
El paisaje natural del Valle Poblano-
}

Tlaxcalteca.

\section{p. $69-83$}

En:

Paisajes patrimoniales. Resiliencia, resistencia y metrópoli en América Latina. III. De lo natural a lo metropolitano / Armando Alonso Navarrete y Mariano Castellanos Arenas, coordinadores. Ciudad de México: Universidad Autónoma Metropolitana, Unidad Azcapotzalco, 2020.

Fuente: ISBN 978-607-28-1996-2 (versión electrónica).

Relación: http://hdl.handle.net/11191/7575

\begin{tabular}{|c|c|c|}
$\begin{array}{c}\text { Universidad } \\
\text { Autónoma } \\
\text { Metropolitana }\end{array}$ \\
$\begin{array}{c}\text { Casa abierta al tiempo Azcapotzalco } \\
\begin{array}{c}\text { Universidad Autónoma Metropolitana } \\
\text { Unidad Azcapotzalco } \\
\text { https://www.azc.uam.mx/ }\end{array}\end{array}$ & $\begin{array}{c}\text { División de Ciencias y Artes para } \\
\text { el Diseño } \\
\text { https://www.cyad.online/uam/ }\end{array}$ & $\begin{array}{c}\text { Mepartamento del Medio } \\
\text { Ambiente }\end{array}$ \\
\hline \\
$\qquad \begin{array}{c}\text { Área de Investigación } \\
\text { Arquitectura del Paisaje } \\
\text { Área de Investigación } \\
\text { Arquitectura del Paisaje }\end{array}$ \\
\hline
\end{tabular}

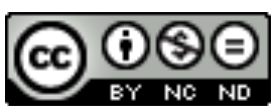

Excepto si se señala otra cosa, la licencia del ítem se describe como

Atribución-NoComercial-SinDerivadas

https://creativecommons.org/licenses/by-nc-nd/4.0/

D.R. (C) 2020. Universidad Autónoma Metropolitana, Unidad Azcapotzalco, División de Ciencias y Artes para el Diseño, Departamento del Medio Ambiente, Área de Investigación Arquitectura de Paisaje. Se autoriza copiar y redistribuir el material en cualquier medio o formato, siempre y cuando se den los créditos de manera adecuada, no puede hacer uso del material con propósitos comerciales, si remezcla, transforma o crea a partir del material, no podrá distribuir el material modificado. Para cualquier otro uso, se requiere autorización expresa del titular de los derechos patrimoniales. 


\title{
El paisaje natural del Valle Poblano-Tlaxcalteca.
}

\author{
Carlos Moreno Pantoja \\ Benemérita Universidad Autónoma de Puebla. \\ carlos_monterop@hotmail.com \\ Yesenia Hernández García \\ Universidad Autónoma Metropolitana, Unidad Azcapotzalco. \\ yehega-8208@live.com.mx
}

Resumen: El presente escrito relata la experiencia profesional y académica que se realizó en el ámbito del Patrimonio Cultural, Natural, Material e Inmaterial, en el marco de la actualización del Plan de Desarrollo de la Zona Metropolitana Puebla-Tlaxcala. La parte que aquí se presenta es lo referente al Patrimonio Natural. Si bien, el patrimonio ya se había considerado en planes y programas pretéritos, en esta oportunidad se ordena, tipifica y categoriza el patrimonio, utilizando los instrumentos de planeación institucionales, el marco jurídico, incluso, solo con datos oficiales. El tema adopta la metodología oficial que, a través de las demandas y los términos de referencia, las instituciones formalizan los ámbitos contratados. ${ }^{1}$ Consecuentemente, así aseguran que la investigación responda a la visión y misión institucionalizada. No obstante, la rigidez oficial, el grupo de investigación abrió caminos para abordar la investigación desde los cuatro ámbitos que propone Querol (2000), en la gestión del patrimonio cultural: conocer, controlar, planear y divulgar. Conocer y divulgar se trabajaron con los cabildos, los encargados de cultura, turismo, así como con los responsables de los edificios religiosos y las zonas arqueológicas, Al mismo tiempo, Controlar y Planear se produjeron desde el colectivo, sesionando como seminario y taller, con lo cual se tuvo un aprendizaje multidisciplinario mutuo que dio como resultado un plan interdisciplinario actualizado.

Palabras claves: elementos naturales, paisaje, transformaciones, crecimiento.

Abstract: This writing relates the professional and academic experience that was carried out in the field of Cultural, Natural, Material and Intangible Heritage, within the framework of updating the Development Plan of the PueblaTlaxcala Metropolitan Area. The part that is presented here is related to Natural Heritage. Although, heritage had already been considered in past plans and programs, on this occasion, the heritage is ordered, typified and categorized, using institutional planning instruments, the legal framework, even, only with official data. The topic adopts the official methodology that, through the demands and the terms of reference, the institutions formalize the contracted

1 En el periodo tratado el método lo definían la SECRETARÍA de Desarrollo Social (SEDESOL), el Consejo Nacional de Población (CONAPO) y el Instituto Nacional de Geografía y Estadística (INEGI). 
areas. Consequently, they ensure that research responds to institutionalized vision and mission. However, the official rigidity, the research group opened ways to approach the research from the four areas proposed by Querol (2000), in the cultural heritage management: knowing, controlling, planning and disseminating. Knowing and disseminating worked with lobbyists, those in charge of culture, tourism, as well as those responsible for religious buildings and archaeological sites. At the same time, control and plan were produced from the collective, sessioning as a seminar and workshop, this resulted in multidisciplinary learning that resulted in an updated interdisciplinary plan.

Keywords: Landscape, transformations, growth.

\section{Introducción.}

La relevancia del patrimonio cultural y natural de la Zona Metropolitana Puebla-Tlaxcala, se valoró conociendo el paisaje desde la dimensión cultural -durante el periodo de 2011 a 2014-, desde luego, en su acepción más elemental cuya naturaleza comprende al lugar, las personas y a sus expresiones tangibles o intangibles.

Como se ha dicho, las instituciones proporcionaron la metodología general. En el ámbito del paisaje no había metodología propia. ${ }^{2}$ Por consiguiente, las bases del "método" fueron acciones empíricas tomadas del campo de los planes y programas de desarrollo urbano, tanto para los registros de los tipos de patrimonio como para la geolocalización, con la cual se produjeron capas, sustratos y mapas que fueron de mucha utilidad para la reflexión, el análisis y el diagnóstico que luego sirvieron para el diseño de las estrategias, los programas y las propuestas.

El punto de partida del paisaje del territorio Poblano-Tlaxcalteca, fueron las dos formas manifiestas en la forma del territorio: el territorio geográfico (más cercano a la idea del Paisaje natural por sus componentes visibles como topografía, montañas, cuencas, bosques, campos de cultivo, etcétera.); además, el territorio construido urbano (inmuebles, calles, mobiliario urbano, vegetación, etcétera). Dentro de esos paisajes se identificaron las unidades de paisaje con los criterios de lugar, es decir, las denominaciones, distinciones o referencias locales (arqueológico, histórico, patrimonial, etc.), siendo esencial el emplazamiento porque, desde allí se buscó la relación inherente al lugar: los procesos, las relaciones o asociaciones, pretéritas o presentes. con lo cual se configuraba el contexto de la unidad de paisaje.

2 Ya empieza a construirse un soporte a partir de las propuestas de Mariano Castellanos en sus investigaciones. 


\section{Problemática del paisaje cultural y natural.}

El primer gran problema es intrínseco al no poseer el paisaje un soporte teórico y metodológico. Por tanto, en el ejercicio profesional son las definiciones y los enunciados los que ayudan a dar claridad a los marcos de referencia. Circunstancia que obliga a recurrir a otras disciplinas en busca de ayuda para construir los elementos propios. ${ }^{3}$

El factor principal identificado es el crecimiento de la mancha urbana metropolitana, que ya rebasa las fronteras urbanas de los estados, municipios que han fusionado la superficie edificada de las localidades a la metrópoli ¿De donde toma la superficie que se apropia? Del suelo agrícola, el bosque, los cuerpos de agua, incluyendo los residuales o la dispersión de los poblados rurales, convirtiéndolos en pueblos urbanos compactos. Este fenómeno tan común para los urbanistas, no lo es en el ámbito del patrimonio cultural y natural, ya que solo se traduce en pérdidas porque acaba con las unidades de paisaje, que tuvieron un origen no urbano, además, con el agravante de que, siendo recursos naturales no renovables, como el suelo agrícola, la vegetación, la fauna, los lechos de agua, etc., desaparecen de los territorios.

Estás circunstancias representan una amenaza y un riesgo permanente para la protección y la conservación de las unidades de paisaje porque vulnera a los grupos sociales quienes deben transformar su hábitat, los rasgos locales, el carácter rural: dispersión, trazado, arquitectura típica, materiales, historia y vegetación, hábitos, costumbres, tradiciones, además de las expresiones inmateriales como el lenguaje y los saberes.

En las zonas urbanas, donde existen polígonos patrimoniales declarados oficialmente como centros históricos; allí, los polígonos solo han servido para que los habitantes consideren a esos lugares urbanos en condición de intocable, pero, fuera de allí, existe absoluta libertad para realizar cualquier tipo de operaciones.

En general, los territorios, los lugares y los tipos de patrimonio están siendo modificados, debido a que la sociedad solo reconoce como propio lo que construye, lo que crea como parte de sus necesidades y práctica cotidiana, por ende, la herencia que recibe se reconfigura sin importar el carácter y estructura original del pasado porque importan el presente y el futuro. Por ejemplo, los lugares urbanos periféricos como los pueblos originarios se deconstruyen para reincorporarlos a la vida cotidiana o se reinventan escenarios como prototipos de la historicidad.

3 Inicialmente lo cultural y patrimonial se apoyaron en el arte y la historia, luego en las disciplinas de la restauración, apoyada a su vez en la medicina y en la arquitectura por sus vínculos con los territorios construidos, entre otros. 
Las arquitecturas de los lugares urbanos ya no tienen homogeneidad formal; las fachadas tienen arreglos personales dominados por los anuncios, alturas, densidades diversas $y$, hasta es posible que definan sus propios tejidos urbanos. ${ }^{4}$ El mobiliario y la señalética (informativa, preventiva y turística), es escasa, no cumple con lo básico porque no orienta a los turistas. ${ }^{5}$

La pérdida del suelo agrícola ha puesto en peligro la producción de los alimentos que son la base del sustento alimentario de los habitantes de las zonas metropolitanas del centro del país, además, son la base de la cultura gastronómica, por ende, muy pronto se dejarán de cultivar los insumos locales con los que se prepara la comida habitual. En el territorio ya se consumen ingredientes que vienen de fuera del entorno culinario de la comunidad, lo cual altera la esencia de la cocina tradicional. Lo más grave es que no hemos sabido defender y, menos aún, sustentar el valor cultural de las cualidades geográficas de nuestro suelo e insumos, con todo lo que implica al tener una posición única en el globo terráqueo (autenticidad e identidad que solo le corresponden a dicho punto geográfico).

En donde hay un atraso considerable es en lo que respecta al Patrimonio Cultural Inmaterial porque no hay registros oficiales, aunque, si se logró identificar componentes de este patrimonio debido a las prácticas festivas habituales activas. Por fortuna, las comunidades no interrumpen las prácticas, las fiestas religiosas ni los rituales; sostienen y difunden los programas de las fiestas patronales, carnavales, realizan los rituales religiosos por sobre cualquier circunstancia (Bodas y otros). El alcance de las expresiones comunitarias trasciende las fronteras de las escalas local y regional; por esta circunstancia, los intangibles no están en riesgo de perderse, pero, suelen transformarse considerablemente porque ya no se sostienen solo aquí y por las generaciones de los viejos sino por los jóvenes. ${ }^{6}$

4 El comercio, así como, los paraderos del transporte público (taxi, combis, microbús, etc.), de los lugares urbanos pequeños, se ubican en los alrededores de la plaza principal, ocasionando conflictos viales a la movilidad y creando riesgos para los peatones, no obstante, el uso central es lo más adecuado, el cableado todavía es aéreo, circunstancia que altera la imagen de los lugares y obstruye la movilidad de personas, además, impide visualizar los inmuebles que son singulares por su belleza.

5 Por ejemplo, para ir hasta Cacaxtla-Xochitécatl, desde la autopista México-Puebla, es complicado, cuando debería ser expedito.

6 Recurrir a los apoyos institucionales para foros y difusión, así como, para la reproducción de danzas, escenificaciones y música suele llevar a otro ámbito las tradiciones, por ejemplo, la "comercialización" del carnaval hace que el sentido original del ritual se pierda, la escenificación se pone en valor económico cuando el consumidor es el turista. Por ello, las comunidades deben diseñar mecanismo de conservación de la práctica carnavalesca desde la elaboración de los trajes típicos hasta la disputa con el látigo. Por ejemplo, el municipio de Papalotla, Tlaxcala, además de poseer cuadrillas carnavalescas producen trajes, máscaras y accesorios. Los pueblos del entorno y otros enseres festivos. 
La artesanía que no está "de moda" no es consumible; la producción de este tipo de objetos transforma el sentido y esencia de la producción de objetos utilitarios comunales. Por consiguiente, para comercializar las artesanías se hacen reproducciones "fidedignas", incluso, certificadas de los bienes considerados en este apartado. La artesanía se descontextualiza al ponerla en el mercado como elemento característico de identidad de una región.

La problemática de los recursos naturales en Puebla aumentó desde los años sesenta, cuando tomó velocidad el crecimiento urbano, desde entonces, los recursos naturales fueron sometidos a una intensa presión y sobreexplotación paulatina, principalmente por cambios en el uso del suelo. La tierra fértil agrícola fue ocupada con vivienda, vialidades y equipamientos; lo que aún queda con cultivos se encuentra amenazado por el crecimiento urbano. ${ }^{7}$

Los elementos naturales afectados presentan los siguientes efectos:

- Contaminación del agua de los ríos porque las zonas industriales y las áreas urbanas arrojan a los cauces las aguas de desecho sin que medie tratamiento.

- Disminución del agua en los mantos freáticos, por ende, el líquido para el consumo humano escasea cada día al no aumentar las recargas del suelo en la misma proporción que la cantidad de población urbana, porque el crecimiento urbano pavimentado reduce la superficie del suelo natural, por tanto, se cancela la recarga de agua a través del suelo.

- Pérdida de zonas boscosas debido a tala inmoderada y a la inserción de asentamientos "Ecológicos" o "Sustentables", que son "amigables" con el medio ambiente. ${ }^{8}$

- Pérdida de ecosistemas con la presencia humana porque se trasforman el hábitat de los seres vivos y desaparecen ecosistemas de fauna y flora.

Lo anterior, nos lleva a concluir que el deterioro de los recursos naturales conlleva no solo a la afectación de la calidad de vida de los habitantes, sino que, en la visión del paisaje cultural, además, se pierden las atmósferas de los tipos del patrimonio, más, todo lo que se vincula con esté: la historia, los mitos, leyendas, tradiciones, costumbres, etc., que son parte de los identitarios que caracterizan al valle Poblano - Tlaxcalteca.

7 Puebla, San Pedro y San Andrés Cholula, Zacatelco, San Pablo del Monte, Cuautlancingo y San Martín Texmelucan.

8 Han proliferado este tipo de urbanizaciones en los parques nacionales y áreas naturales protegidas. No pasará mucho tiempo para que se metan al cráter del volcán. 
Las causas reales de esta tendencia metropolitana no se han estudiado, consecuentemente, tampoco se tienen escenarios del peligro ecológico y cultural que conlleva.

\section{Para entendernos. El paisaje y el patrimonio.}

Para hacer el registro del patrimonio tomamos de base los conceptos y definiciones de UNESCO (Las convenciones sobre los tipos de patrimonio, paisaje, etcétera), la Ley Federal de Monumentos y las leyes correspondientes de los estados de Puebla, Tlaxcala y de sus municipios.

De acuerdo con la Convención sobre la Protección del Patrimonio Mundial, Cultural y Natural (1972), en su Artículo 2 se considera "Patrimonio Natural":

- Los monumentos naturales constituidos por formaciones físicas y biológicas o por grupos de esas formaciones que tengan un valor universal excepcional desde el punto de vista estético o científico.

- Las formaciones geológicas y fisiográficas y las zonas estrictamente delimitadas que constituyan el hábitat de especies, animal y vegetal, amenazadas, que tengan un valor universal excepcional desde el punto de vista estético o científico.

- Los lugares naturales o las zonas naturales estrictamente delimitadas, que tengan un valor universal excepcional desde el punto de vista de la ciencia, de la conservación o de la belleza natural.

Por la importancia del Patrimonio Natural, se debe identificar, proteger, conservar, rehabilitar y transmitir a las generaciones futuras (Artículo 4).

Una vez entendido el concepto del patrimonio se pasa a diferenciarlo según sus cualidades, valores y estatus jurídico. Si aportamos en ordenar y dar claridad a los patrimonios legalizados. Incluimos, además, criterios y consideraciones no contenidas en los instrumentos considerando lo más valioso cuantitativa y cualitativamente.

\section{Tipos de patrimonio.}

Para determinar los tipos de Patrimonio se hizo una combinación entre las definiciones (que ya de por si tienen su valor jurídico) y las disposiciones establecidas en las leyes y los decretos específicos (Nacionales o Estatales), así tenemos:

\section{Patrimonio Cultural (PC):}

- Monumentos Históricos (MH)

- Monumentos Arqueológicos (MA)

- Monumentos Artísticos (Mart) 
- Zona de Monumentos Históricos (ZMH)

- Zona de Monumentos Arqueológicos (ZMA)

- Zona de Monumentos Artísticos (ZMArt)

- Poblaciones Típicas (PT)

- Zona Típica Monumental (ZTM)

- Pueblo Mágico (PM)

\section{Patrimonio Natural (PN):}

- Monumentos Naturales

- Formaciones Geológicas

- Formaciones Fisiográficas

- Zonas de Hábitat

- Zonas Naturales

- Área de Belleza Natural

- Área Natural Protegida

- Reserva de la Biosfera

- Parque Nacional

\section{Patrimonio Cultural Inmaterial (PCI):}

- Lengua, Tradiciones y Expresiones Orales.

- Rituales y Actos Festivos: Expresiones musicales, Danzas tradicionales, ceremonias y festividades tradicionales, y Ritos y sitios sagrados.

- Conocimiento y manejo de recursos naturales.

- Conocimiento de medicina y herbolaria tradicional.

- Cocinas tradicionales, sabores culinarios y prácticas domésticas.

- Técnicas Artesanales Tradicionales (Artes y oficios tradicionales).

\section{Categorías del patrimonio.}

También, las convenciones mundiales, las leyes nacionales, las estatales y las municipales han definido las categorías del patrimonio; para efectos de este estudio únicamente se ordenan y se les proporciona un nombre:

1. Distintivo UNESCO (DU). Patrimonio con valor Universal validado por UNESCO. También el patrimonio que obtenga algún distintivo internacional. Aquí se considera también el patrimonio que se encuentra en lista indicativa para ser validado por UNESCO o cualquier entidad internacional.

2. Categoría A (CA). Patrimonio validado nacionalmente, con declaratoria o Ministerio de Ley. 
3. Categoría B (CB). Patrimonio con valor estatal (Regional), con declaratoria o Ministerio de Ley.

4. Categoría C (CC). Patrimonio con valor Municipal (Local o vernáculo, aplica a la localidad), asumido por la entidad en sus reglamentos y programas. Aquí se considera el Patrimonio con valor sin declaratoria o Ministerio de Ley pero que es importante para la historia o la comunidad o porque son bienes que por alguna circunstancia no han sido valorados y registrados (Bienes de interés cultural o BIC).

\section{Caracterización general de los elementos del patrimonio cultural y natural de la Zona Metropolitana Puebla-Tlaxcala (ZMPT).}

Territorialmente la zona metropolitana se encuentra entre tres de las cuatro elevaciones más grandes de México: Popocatépetl, Iztaccíhuatl, y Malinche; estás elevaciones a través del tiempo han servido de protección y cobijo a los diversos seres vivos existentes; además, de dotar de agua, tierras fértiles y protección en la regulación de la temperatura ambiental.

La Zona Metropolitana Puebla-Tlaxcala (ZMPT) contiene valioso patrimonio cultural, natural e inmaterial, entre los cuales, destacan los monumentos históricos, religiosos y civiles; en lo inmaterial, la gastronomía, las fiestas y tradiciones, la música, las leyendas, etcétera. Estos distintos tipos de patrimonio conforman significativos paisajes naturales (Unidad de Paisaje), es decir, espacios verdes, vistas a distancia, perfiles orográficos, áreas arboladas, bosques, campos agrícolas, granjas, lagunas, etcétera. Así, el paisaje de la ZMPT está constituido con elementos geográficos naturales como la orografía volcánica del Popocatépetl, Iztaccíhuatl, Malinche y Cuexcomate. La cúspide se congela; los perfiles que figuran el paisaje son efímeros, porque cambian sucesivamente por fenómenos físicos y por temporadas, no obstante, son cambios visuales, con los que se identifican los habitantes de la parte baja del territorio.

Los paisajes se forman con el deshielo de los volcanes; el agua helada en las barrancas, ríos (Zahuapan y Atoyac), y arroyos, cuerpos y depósitos de agua (lagunas y jagüeyes); la abundancia del agua y el suelo posibilita el cultivo, incluso en la parte alta con la técnica de terrazas (paisaje agrícola orográfico).

Debido a la altura de los volcanes las montañas son discretas por los perfiles bajos que configuran, son "pequeñas" montañas sobre las que se construyeron algunas de las ciudades prehispánicas. 
En torno a las tres elevaciones antes mencionadas se configuran otros atributos naturales:

- Escurrimientos de los volcanes que en su bajada a los valles configuran ríos (Zahuapan, Alseseca y Atoyac); arroyos, lagunas y jagüeyes.

- Tierras fértiles para el cultivo de maíz, fríjol, trigo, amaranto, árboles (de distintos tipos), así como la variedad de verduras, entre algunos.

- El agua suministrada por los volcanes ha propiciado las condiciones necesarias para la actividad agrícola y el consumo humano.

- Flora de diferente tipo de especies, distribuidas en diferentes áreas y alturas, entre las que se encuentran árboles frutales, arbustos, pinos, flores, entre otros.

- Fauna de especies diversas entre mamíferos, reptiles, aves, etc.

De lo expuesto, la ZMPT sólo ha sido distinguida, mediante Decreto Oficial Federal, con la denominación de Área Natural Protegida o Parque Nacional, a los lugares siguientes:

Parque Nacional Malinche o Matlalcuéyatl: Fue declarado Parque Nacional el 06 de octubre de 1938, forma parte de la cadena montañosa conocida como Eje Neovolcánico Transversal, sobresale por su diversidad de especies en flora y fauna, y porque constituye una fuente importante de abastecimiento de agua para la región, además de su valor histórico y cultural. La superficie protegida se ubica en la parte alta del volcán y compete a los Estados de Puebla y Tlaxcala proteger y conservar la superficie de 46,112.241416 hectáreas.

Parque Nacional Iztaccíhuatl-Popocatépetl: Fue declarado el 08 de noviembre de 1935 y en 2010 la UNESCO lo clasificó cono reserva de la Biosfera, con una superficie de 172 mil hectáreas. Se localiza en los estados de México, Puebla y Morelos. Por sus características naturales es un importante depósito de especies de flora y fauna (algunas de ellas endémicas). Destaca por su biodiversidad y riqueza de sus ecosistemas, ya que aportan servicios ambientales como bienes faunísticos, vegetales y minerales que han sido aprovechados por los habitantes de la región y su área de influencia.

Reserva Estatal Sierra del Tentzo: Declarada área natural protegida ${ }^{9}$ tiene una superficie de 57, 815. 28193 hectáreas. Por sus características naturales

9 Comprende a los municipios de Atlixco, Atoyatempan, Huaquechula, Huatlatlauca, Huehuetlán El Grande, Molcaxac, Teopantitlán, Tepeojuma, Ocoyucan, Puebla, San Diego la Mesa, San Juan Atzompa y Tzicatlacoyan, todos en el Estado de Puebla. 
alberga un gran número de especies en flora y fauna (algunas especies consideradas endémicas).

Además, de lo anterior encontramos los perfiles orográficos de los cerros que se levantan en áreas específicas como el cerro de San Juan, los cerros de Loreto y Guadalupe, el cerro del Tepoxuchitl, el arbolado de Flor del Bosque y los cerros Totolqueme y Mendocinas en San Martín Texmelucan.

La riqueza eminentemente natural de orografía, flora y fauna de los volcanes, un valor paisajístico extraordinario cuyas vistas, desde cualquier punto de la ZMPT, son referentes naturales identitarios compartidos que, con toda seguridad, condicionaron el establecimiento y trazado de los asentamientos y su arquitectura partiendo del infinito de las visuales. También los terrenos de cultivo caracterizan a algunas regiones, por ejemplo el cultivo de flores a Atlixco, carácter que también tuvieron San Pedro y San Andrés Cholula; los suelos agrícolas caracterizan a la mayor parte del territorio de la ZMPT exceptuando la zona conurbada de la Ciudad de Puebla pero, como la agricultura está asociada a otros aspectos de la vida cotidiana como la religión y los ritos se mezclan con la festividad.

El patrimonio natural vale por su connotación de recurso natural y parte esencial de un sistema de ciclos ecológicos del medio natural por eso, es alarmante que esos ciclos del sistema se estén alterando y destruyendo por intereses económicos, sobreexplotación, ignorancia y negligencia. Llama la atención la contaminación del agua de todos los cauces, no hay uno que se salve; si eso no fuera suficiente, con esa agua contaminada se riegan los cultivos.

\section{Descripción histórica de los elementos naturales.}

Los elementos naturales no solo han sido parte de la supervivencia y hábitat de diversas especies, sino también, son referentes y símbolos de la vida cotidiana, costumbre y creencias de los habitantes; en este sentido, así lo enfatiza la investigadora Serra Puche:

La orientación exacta de los edificios de la Zona Arqueológica Xochitécatl (localizada en el municipio de Natívitas, Tlaxcala) sugiere una interpretación ritual del paisaje natural, es decir, el lugar de construcción fue elegido. La localización de cada uno de los edificios parece expresar una particular cosmovisión y, más especificamente, un nexo entre los volcanes y el hombre. ${ }^{10}$

Además de lo anterior, existen innumerables relatos, cuentos, mitos y leyendas en torno a los volcanes, ríos, lagunas y cerros, por lo que intentar desvincular al hombre de su medioambiente y más aún olvidarlo es perder

10 Serra Puche, Xochitécatl, pág. 131 
parte de su identidad y simbolismo. Los relatos realizados por cronistas durante la conquista describían los rasgos particulares del territorio, pero, sobre todo, de aquellos que resultaban de gran sorpresa y agrado. Lo describen como un lugar donde hay sierras muy altas, sobre las cuales todo el año tiene nieve, en un tiempo más y en otros menos; junto a la nieve hay rocas y riscos muy ásperos. El relato continua con una descripción más detallada de un cerro o volcán que resulta peculiar por sus características y porque se encuentra activo:

Hay un cerro altísimo o volcán en forma piramidal y aguzada, tan alto como la Sierra Nevada sobredicha, en cuya cumbre a la parte de oriente tienen una boca por la cual ordinariamente echa cada día por la mañana, y algunas veces mañana y tarde, gran cantidad de humo muy espeso y condensado, el cual, hecho una nube muy grande y muy gruesa, se suele extender y alejarse una y dos y más leguas a donde el viento le lleva; deste humo y fuego sale gran cantidad de ceniza con que está cubierto gran pedazo del mesmo volcán allá arriba junto a la boca, y aun a veces suele llevar el viento aquella ceniza cuando sale por la boca sobredicha y arrojarla media legua, y aun una más, de allí. ${ }^{11}$

Aunque en el relato no se menciona el nombre de dicho cerro o volcán es muy probable que se trate del Popocatépetl. Tan rico y vastos eran los recursos naturales del valle poblano-tlaxcalteca que existen descripciones precisas realizadas por cronistas, en las descripciones se logra reconstruir la belleza y lo maravilloso del lugar, no es de extrañarse que los conquistadores quedaran maravillados por el nuevo continente y sus riquezas naturales. En la descripción del territorio de la ciudad de Puebla se resalta los rasgos del clima, suelo, agua, materiales y perfiles orográficos:

La ciudad de Puebla de los Ángeles es un pueblo de españoles, de mucha vecindad, y va cada día aumentándose y en crecimiento, porque dentro del mesmo pueblo se saca cuanta piedra es menester para los edificios y se hace abundancia de cal, la cual vale barata; la madera se trae de la Sierra de Tlaxcalla, cuya falda llega casi a la mesma ciudad; muy por allí así para el servicio de la ciudad y traerle provisión, hay infinidad de carretas de bueyes y de mulas. Es tierra fría y seca y de buena y fértil comarca, aunque tiene un gran contrapeso, y es que por estar entre la

11 Antonio de la Ciudad Real I, Tratado curioso y docto de las grandezas de la Nueva España. Relación breve y verdadera de algunas cosas de las muchas que sucedieron al Padre Fray Alonso Ponce en las provincias de la Nueva España siendo comisario general de aquellas partes, pág. 98 
sierra de Tlaxcalla sobredicha y entre el volcán y Sierra Nevada de México hay en aquella ciudad entre años, en tiempote aguas, muchas y muy grandes tempestades de truenos y relámpagos y caen muchos rayos. Junto a la ciudad y aun dentro Della nacen muchas fontecillas de agua caliente, sucia y de mal olor, que dicen es de piedra azufre, la cual no hace mal sino mucho bien a las bestias que la beben, y es maravillosa para hacer barro y cal para los edificios, y para regar las huertas, pero no beben della los españoles ni los indios, que para esto viene un buen golpe de agua muy buena a la ciudad, por la cual se reparte encañada, y en medio de la plaza tiene hecha una fuente muy curiosa de piedra labrada, con muchos caños que salen y se ceban de la mesma agua; por junto a nuestro convento corre un arroyo de razonable agua, con la cual muelen allí junto unos molinos y andan batanes, y pasáse por una puente de piedra para entrar al convento. ${ }^{12}$

El imaginario evoca la riqueza natural extraordinaria con la que contaba la ciudad de Puebla, rica en materiales de construcción, tierra fértil y agua, favoreciendo e impulsando así, el desarrollo y consolidación de la ciudad.

En lo que se refiere al territorio Tlaxcalteca, citamos el siguiente testimonio histórico que hace referencia a los rasgos naturales más sobresalientes del territorio:

Es desolado y frío, contienen varios amplios valles y llanuras que atraviesan la división continental a una altura de 21002600 metros, con el volcán de La Malinche (Matlalcuéyatl), que alcanza a 4460 metros, en la frontera sureste. La mayor parte desagua hacia el sur por el sistema del Atoyac, aunque una pequeña parte lo hace hacia el Tecolutla (golfo) y la parte oriental pertenece a la cuenca de drenaje interior de los llanos de San Juan. Las Iluvias son estaciónales moderadas. La intensa erosión ha eliminado la mayor parte del suelo y la vegetación natural. El área ocupa casi todo el actual Estado de Tlaxcala, con excepción de su extremo occidental. ${ }^{13}$

Mediante las descripciones históricas pudimos prefigurar que en el valle poblano tlaxcalteca existía diversidad de climas, suelos, orografía, vegetación, etc. Construir el imaginario con la riqueza de los recursos que

12 Antonio de la Ciudad Real I. Tratado curioso y docto de las grandezas de la Nueva España. Relación breve y verdadera de algunas cosas de las muchas que sucedieron al Padre Fray Alonso Ponce en las provincias de la Nueva España siendo comisario general de aquellas partes, pág. 85-86.

13 Meter, Geografía histórica de la Nueva España 1519-1821, pág. 333 
poseía el territorio nos arroja los rasgos naturales del territorio PoblanoTlaxcalteca nos permite.

Si comparamos la descripción histórica con la situación actual nos damos cuenta de la devastadora transformación y perdida de los recursos naturales. El crecimiento urbano de Puebla ha devorado y está asfixiando los pocos espacios naturales existente, no por algo es la cuarta metrópoli de México. Buena parte de los elementos naturales descritos han sido transformados y/o desaparecido, a través de los años, para darle lugar a lo construido (La zona metropolitana de Puebla y Tlaxcala), como necesidad natural de los habitantes y de las relaciones funcionales existentes (conurbación de varios municipios).

\section{Conclusiones.}

A través de los años, la devastación y depredación de los recursos ha sido impresionante, sobre todo porque no se buscó generar un equilibrio entre las áreas construidas y las naturales.

Los factores que fueron decisivos en el crecimiento urbano acelerado de Puebla fueron: la industrialización, la creación y ampliación de la estructura viaria, la construcción de vivienda en zonas periféricas y la creación de equipamientos de alto impacto como los centros comerciales, mercados, hospitales, escuelas, etcétera.

Hasta el momento se puede concluir que no es factible seguir con el mismo modo de crecimiento urbano, porque se terminaría con los recursos naturales que sirven de sustento y cobijo no solo a la población de Valle Poblano Tlaxcalteca, sino a otros ecosistemas. El territorio mismo con su orografía conforma un contexto paisajístico inigualable que se complementa con los escurrimientos de agua cuyos caudales forman arroyos, ríos, barrancas y depósitos de agua; en ese territorio cultural formaron su hábitat, mezclados de vegetación con plantas diversas y animales.

El respeto por los elementos naturales debe ser prioridad para garantizar la calidad de vida de los habitantes y conservar el patrimonio natural que es parte de la identidad heredada por generaciones pasadas.

Además, el territorio de la ZMPT posee un importante Patrimonio Cultural e Inmaterial de gran valor histórico, social, arquitectónico, arqueológico y urbano. En ambos territorios los seres vivos construyen el hábitat de las personas, los animales, las plantas, etc., formando ecosistemas relacionados y estratificados diacrónicamente, con los que forman el Paisaje Cultural, así como las diversas unidades de Paisaje (subsistema o microsistema). 
Por tanto, las unidades de paisaje que no consiguen la categoría de monumento, sí configuran un paisaje cultural local.

Lo que no había sucedido a los centros históricos y pueblos originarios, hoy les está sucediendo con proyectos zonales.

El desequilibrio metropolitano es un indicativo de que algunos o todos los componentes del sistema no funcionan adecuadamente y que, por consecuencia, pueden colapsar. El equilibrio es la armonía, por tanto, la ZMPT debe ser un sistema de asentamientos humanos y centros de población relacionados y articulados, no solamente en lo físico sino, sobre todo, en lo histórico y lo cultural.

Cada lugar debe participar en el sistema metropolitano destacando y poniendo en valor lo propio: su historia (Patrimonio), sus expresiones tangibles e intangibles (Patrimonio Cultural) y su vocación natural; por su parte, la ZMPT, reconociendo y respetando la diversidad cultural, entendida como el cúmulo armónico de los elementos locales con los cuales se fortalecen sus raíces, identidad, cohesión social, participación ciudadana, potencia sus recursos como producto de desarrollo económico, social y cultural.

\section{Reflexiones finales.}

Resulta substancial comprender como la naturaleza y el hombre han sido elementos que se condicionan, se complementan y, en ciertos momentos históricos, son antagónicos por la actuación natural del hombre para transformar el entorno, provocando con ello desequilibrios sustantivos a los medios natural y construido. Por consiguiente, el Paisaje está amenazado por factores que lo transforman y alteran día a día.

La huella histórica muestra qué, para la existencia de lo urbano, se ha tenido que destruir y transformar lo natural. Efectivamente, es visible en la forma del territorio que las transformaciones, deterioro y/o pérdida de los elementos naturales del territorio han sido consecuencia del crecimiento urbano del Valle Poblano-Tlaxcalteca. ${ }^{14}$

Reflexionamos sobre la problemática central, al final, las proponemos como premisas: primero, qué el desarrollo urbano no debe ir por encima del desarrollo humano. Segundo, que no es viable para la conservación de los paisajes patrimoniales seguir con el mismo modelo de urbanización en las metrópolis. Tercero, que los discursos oficiales como el de Hábitat III, son sustantivos, pero, también deberían aportar los instrumentos para

14 Así, el crecimiento urbano se convierte en un ente invisible en su causalidad, al que se le pueden atribuir todo tipo de responsabilidades sin necesidad de conocer a las causas verdaderas. 
poder aplicarlos a la realidad, asegurando la protección, conservación y puesta en valor de lo natural: suelo, cultivos agrícolas, reservas naturales, áreas verdes, cerros, ríos, etc.

\section{Referencias.}

Antonio de la Ciudad Real I, Tratado curioso y docto de las grandezas de la Nueva España. Relación breve y verdadera de algunas cosas de las muchas que sucedieron al Padre Fray Alonso Ponce en las provincias de la Nueva España siendo comisario general de aquellas partes. Edición, estudio, apéndices, glosarios, mapas e índices por Josefina García Quintana y Víctor M. Castillo Farreras, Volumen I Universidad Nacional Autónoma de México, 1993. Pág. 85-86 y 98.

Convención sobre la Protección del Patrimonio Mundial, Cultural y Natural. UNESCO, 1972.

H. Ayuntamiento del Municipio de Puebla, Actualización del Programa de Desarrollo Urbano de la Ciudad de Puebla, Gobierno del Estado de Puebla. México, $2^{\text {a }}$ Edición, 1994.

Mazurek H. (2006). Espacio y Territorio. Instrumentos metodológicos de investigación social . La Paz, Bolivia: Fundación PIEB.

Meter Gerhard, Geografía Histórica de la Nueva España 1519-1821, Universidad Nacional Autónoma de México, 1986. Pág. 333.

Montero Pantoja, Carlos, La Renovación Urbana. Puebla y Guadalajara: Un estudio comparado, Instituto de Ciencias Sociales y Humanidades, Benemérita Universidad Autónoma de Puebla, 2002.

Serra Puche, Mari Carmen, Xochitécatl, Gobierno del Estado de Tlaxcala, Instituto Tlaxcalteca de la Cultura y Consejo Nacional para la Cultura y las Artes. Segunda edición, 2012.

Consulta en línea: Secretaría del Medio Ambiente y Recursos Naturales, fecha de consulta 16 de octubre de 2017, página web: https://www.gob.mx/semarnat/ articulos/parque-nacional-iztaccihuatl-popocatepetl?idiom=e 